\title{
The Historic Urban Landscape and the Metropolis
}

\author{
Eric Huybrechts
}

Institut d'aménagement et d'urbanisme d'lle-de-France (IAU-IdF), Paris, France

Email: eric.huybrechts@iau-idf.fr

\begin{abstract}
The Historic Urban Landscape (HUL) recommendation adopted by UNESCO in 2011 provides a holistic approach based on landscape planning principles. It is in line with the International Guidelines for Urban and Territorial Planning adopted by UN-Habitat in 2015 (UN-Habitat 2015). HUL concerns the integration of culture in territorial planning processes and the historical urban centre inside their urban or city context. Large cities are becoming the dominant pattern of the human settlements worldwide. They are the main engine of economic development, attracting people for jobs, creating the highest values and are the main support for the globalisation process. The $21^{\text {st }}$ century is the era of the metropolis, with a large increase of cities of more than 500,000 inhabitants. The heritage of the $21^{\text {st }}$ century will be building through the metropolis. We can consider the metropolis as an artefact of the humankind. It produces large urban-rural systems supported by large infrastructures, iconic buildings and specific facilities. The upgrading of the main characteristics of the metropolis adds value in cities for the quality of life, creating new heritage at a scale greater than the existing world heritage categories. HUL could be extended as a relevant approach to be applied on the metropolitan scale.
\end{abstract}

KEYWORDS Historic Urban Landscape, metropolis, heritage, territorial planning

Received March 12, 2018; accepted December 22, 2018.

\section{Introduction}

Metropolitan areas are accommodating more than $50 \%$ of the urban population in the world and this rate increases (United Nations 2018). Each year 20 cities are reaching the size of a metropolitan area of more than 500,000 inhabitants. We can consider the metropolis as a main feature of the human settlement pattern, the dominant artefact of the humankind for the $21^{\text {st }}$ century.

The metropolis is both one of the main tools and the effect of the globalisation process. It is the spatial organisation of the most productive areas concentrating public and private headquarters, high level of investments for creative industry, cultural facilities and innovation. They are considered as the engine of growth for countries and regions. The GDP of the largest metropolises are larger than several countries ${ }^{1}$.

They should be managed at the scale of the city system that covers both urban and rural areas, participating in the same territorial system. Managing metropolitan areas is complex and requires specific governance bodies. The diversity of services needs the coordination of public and private investments and operations. The diversity within territories with dense urban areas and natural or agricultural resources, or megaprojects and scattered urban developments, or rich and productive areas compared to decayed and popular neighbourhoods, requires political platforms to share challenges and prepare decisions.

Given the specific role of the metropolis within the globalisation process, communication infrastructures are essential. It gathers together international airports, railway stations, harbours, logistic hubs, and the main connection facilities as exhibition centres, conference centres or central business districts, that can be considered as their main landmarks. Real estate is becoming highly speculative due to the globalisation of finance by shaping metropolitan areas for high level products and excluding a large part of the population from the city centres. Metropolitan areas are bipolarising $^{2}$ with high class districts and low integrated areas or slums. These products are the key artefacts of our present.

Metropolises are competing for attracting investments, headquarters and high class experts. City marketing is becoming a key tool for supporting city development 


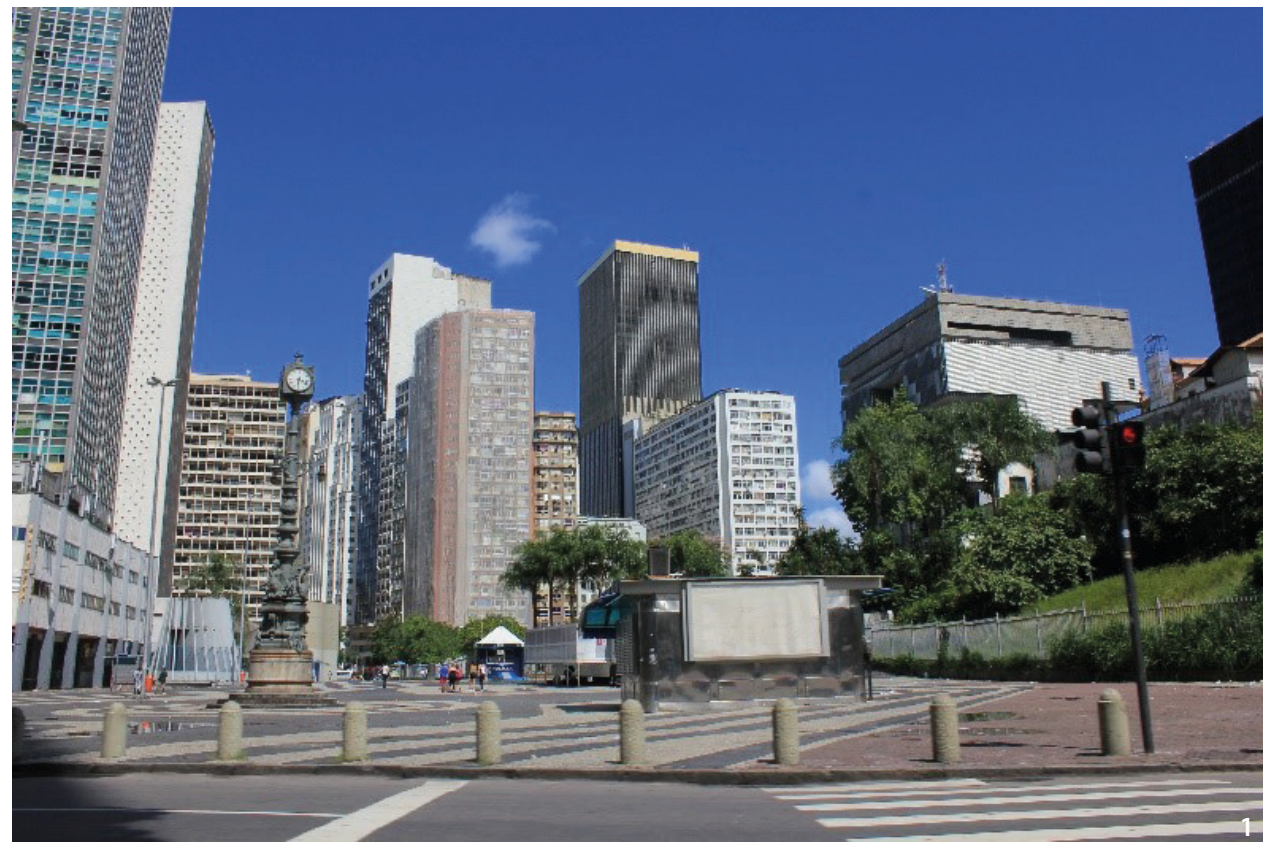

Figure 1 Central business districts for competitive cities (Rio de Janeiro city centre) (Source: the author). strategies together with branding the city through several touristic features as culture, heritage, health industry, shopping and entertainment. In the present economic competition, it is essential to position large cities on the world map. The historic precincts, opera houses, main cultural facilities, large shopping malls, luxury general hospitals or leisure parks are being identified as important facilities to produce vibrant cities with cultural life and leisure and making cities more attractive.

To upgrade their position, cities are implementing specific policies for tourism and identity that reshape their physical features and land use organisation: restructuring of waterfronts in Istanbul, Rio de Janeiro and Shanghai; adaptive reuse of the commercial harbours for shopping and entertainment in Barcelona, Hamburg and Cape Town, docklands reconversion in London and Mumbai, and even new Central Business Districts in Beirut and Tokyo. Urban renewal is a key mode of action in the globalisation processes (Figure 1).

Cities are commissioning iconic buildings as landmarks to distinguish themselves from the others, following the examples of the Eiffel Tower, the Gate of India, the Sydney Opera House, Burj Khalifa, Petronas or the Bilbao Guggenheim Museum. Starchitects are mobilised to produce extravagant designs to show their cities at the edge of the innovation. These products focus on their own design without taking into account the context, contributing to the disorientation of the urbanisation.

Due to the importance of the metropolis ${ }^{3}$, international organisations mobilise researchers to clarify definitions, to analyse the complex systems of governance, to identify the drivers of the territorial dynamics. Territorial planning agencies are established ${ }^{4}$, and a new global network of Metropolitan and Territorial Planning Agencies ${ }^{5}$ have been launched in 2016 during the UN-Habitat III conference in Quito.

But the heritage of the metropolis is more complex than an addition of individual conservation area, iconic buildings and outstanding landscapes. As shown here above, the metropolis should be considered as a product of the globalisation with specific artefacts that are subject to fast changes. Iconic buildings compete with other new iconic buildings. International airports are displaced due to city expansion and strong growth of flight traffic. Shopping malls are disappearing due to e-shopping and change of behaviours. Large infrastructures are reconsidered for new shapes and functions.

The creative industry becomes a way to transform the city from within. It represents an important economic asset, for example being 9\% of the employment of Paris Region (WCCF 2018). Local initiatives from citizens, with the support of private investors and sometimes the municipalities, are triggering dozens of city transformations in large metropolises as shown in Shanghai M50 or the temporary urbanism in Paris that becomes permanent. Here, culture is a tool for urban renewal, a challenge for making the 'compact cities' (Figure 2).

The scale of the metropolis supports the city expansion within its own space. The permanent structure of a metropolis is based on four basic grids comprising the 


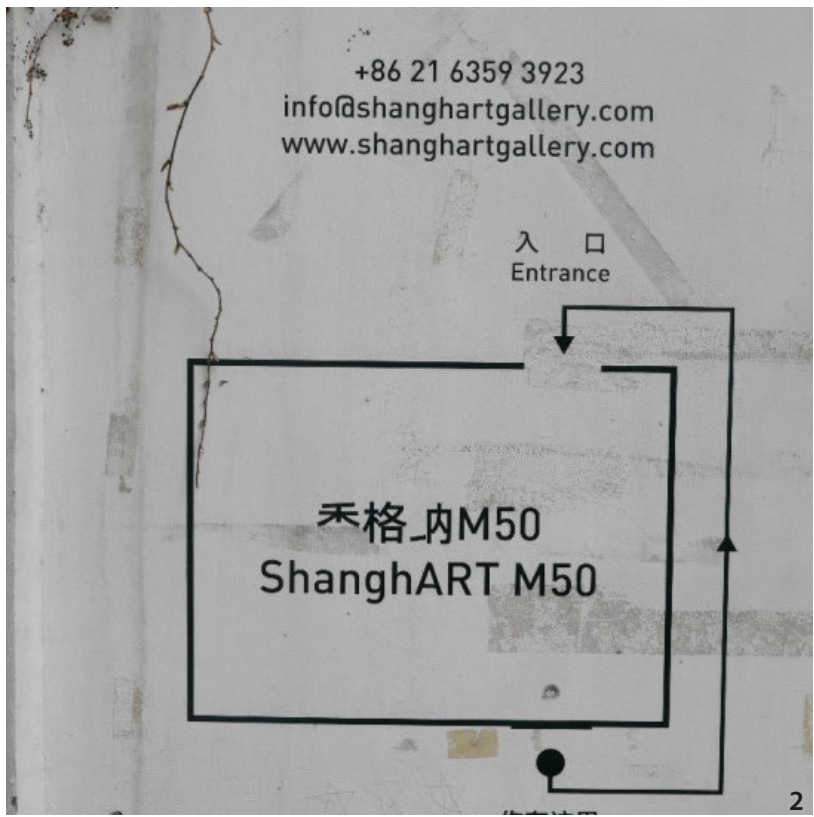

Figure 2 Tactical urbanism, when culture fit with urban renewal, M50 in Shanghai (Source: the author).

physical structure of the city: blue, green, grey and white grids representing the major landscape features including the geomorphology, water, green corridors and forests together with the main public spaces, streets, motorways, squares and railways, and key energy and telecommunication infrastructures. The heritage conservation and enhancement principles need to be applied in these areas not only as a priority but as a new formula for management. How do we preserve and upgrade these areas to make them valuable features for the metropolis? Several cities are operating drastic changes in these areas by reshaping their physical infrastructures. For example, Seoul transformed a highway to recover a river in the city centre, Boston covered a major artery to provide new amenities and the Paris Regional Master Plan restructured with green corridors and urban green grids. These large grids are the heritage backbone of the metropolis.

Metropolitan areas are both urban and rural. Their ecosystem is based on the symbiosis between the urban agglomeration and its hinterland which includes the metropolitan landscape and its biodiversity. This is an essential interrelationship to be considered for its visual and physical linkages extending from the rural areas to the core part of cities. For example, the role of rivers in connecting the city centres to the natural areas is essential. Major efforts made by several cities to reintroduce nature in cities are for the most part based on river beds that are key linear support systems transcending different territories. Territorial management of rural areas are also being developed, based on natural and cultural heritage thereby fostering socioeconomic development. Several regional natural parks, in France ${ }^{6}$ and Italy or similar projects in Lebanon and China, and landscape protection areas are implemented in the hinterland of metropolitan areas to enhance the quality of life at the periphery of the agglomeration and foster a socio economic development based on cultural and natural heritage preservation and enhancement.

The contemporary challenges of human settlement are reshaping the metropolitan areas with the Historic Urban Landscape (HUL) approach providing a holistic methodology for managing territories and cultural/natural heritage. After the protection of monuments, historic precincts and cultural landscapes, the metropolis should be considered as a new scale and object for heritage conservation and enhancement as one of the main artefacts of the $21^{\text {st }}$ century. It requires new definitions and management tools in the international framework of the World Heritage, well adapted to a metropolis that is subject to permanent transformations.

Due to its importance and complexity, the metropolis is subject to a multiplicity of opinions and researches. But the heritage of the metropolis is not yet considered as an issue to be debated. The scientific debates at the city scale are more oriented to city marketing or city branding, city representations and the image of the city, the urban identity or how tourism policies manoeuvre culture (Lussault 1992; Debarbieux 2012; Houillier-Guibert 2012). On the other side, researches on heritage and on the processes for turning assets into heritage are based on existing categories, mainly monuments, sites, architecture, historic urban centres and ensembles, landscapes and biodiversity (Grange and Poulot 1997). As they are not focusing on the metropolis as a heritage several questions need to be asked. In what way are metropolitan areas representing the main feature of humankind in the $21^{\text {st }}$ century? How will territorial planning re-shape the metropolitan areas? How is the heritage of the metropolitan area evolving? What are the elements and attributes of a metropolitan heritage? And lastly, how can the HUL approach be extended to the metropolitan scale?

\section{Structure of the Present Paper}

The present paper is organised in three main parts. The first part is dedicated to depicting human settlement patterns of the present period with a focus on the metropolitan areas. Large metropolises are changing the way we manage territories and their economic development and are producing specific spatial organisation that shape our societies. 


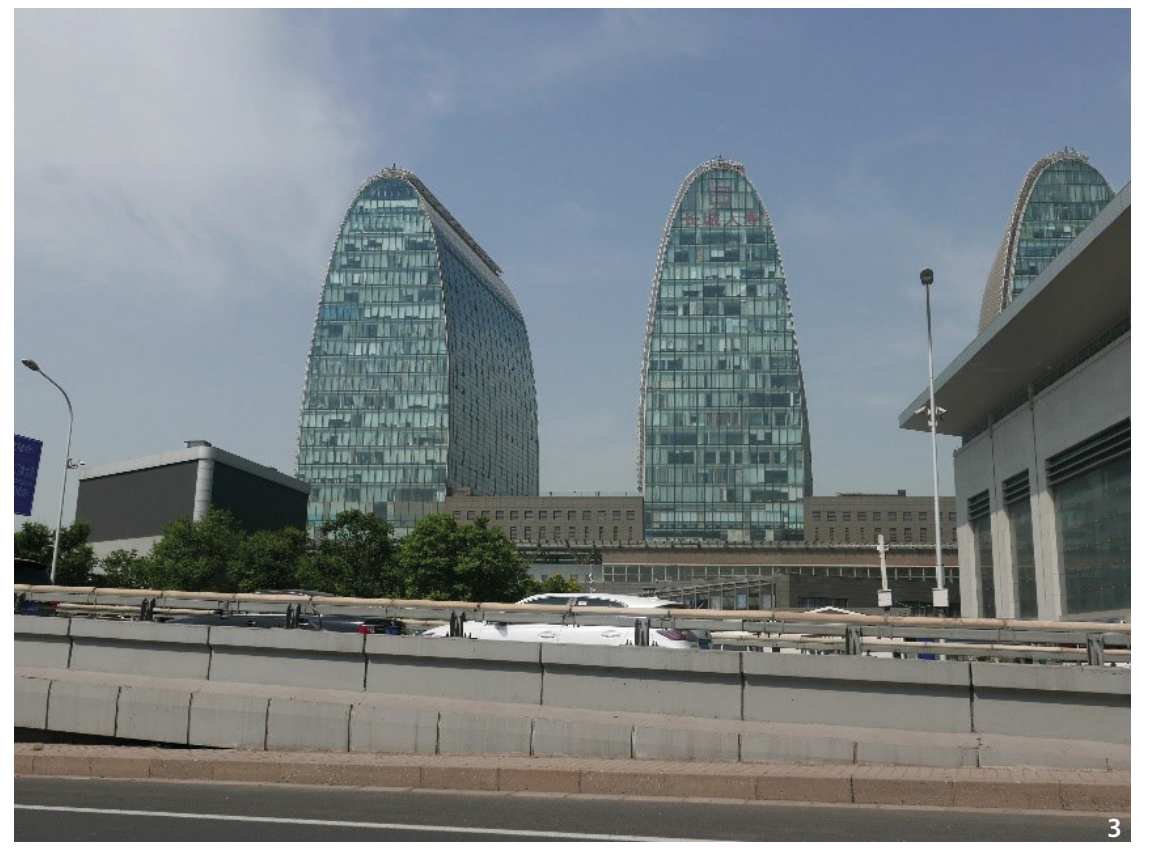

Figure 3 Contemporary architecture, to create metropolitan heritage of tomorrow (the CapitaMall near Beijing North Railway Station) (Source: the author).
The second part focuses on the evolution of territorial planning in the last decades. It shows how urban planning adapts its approach due to the main changes in the governance systems and the new challenges cities are facing. These new approaches on territorial planning focus less on plans but are looking for institutional and technical frameworks and processes to support sustainable development.

The third part discusses the role and the importance of culture in metropolitan planning. It proposes a tentative identification of metropolitan heritage and a possible extension of the HUL approach to the scale of the metropolis representing the current patterns of human settlements.

The conclusion of the paper discusses how metropolitan heritage could take into consideration the methodology of the HUL approach (Figure 3).

\section{The Era of the Metropolis}

The $21^{\text {st }}$ century begins with large metropolitan areas that are the dominant type of organisation of human settlements (OECD 2015).

A consensus has been reached on the definition of a metropolitan area: OECD approved in 2011 a methodology to identify the functional urban areas that is a harmonised definition of urban areas as 'functional economic units' (OECD 2013). It is based on a core urbanised areas or 'urban high-density clusters', ignoring administrative borders based on a population grid of $1 \mathrm{~km}^{2}$. An urban core consists of a high-density cluster of contiguous grid cells of $1 \mathrm{~km}^{2}$ with a density of at least 1,500 inhabitants per $\mathrm{km}^{2}$ (1,000 inhabitants in Canada and USA) and the filled gaps that could be mono or polycentric (when more than $15 \%$ of the population commute to another core urbanised area). A municipality is defined as being part of an urban core if at least $50 \%$ of the population of the municipality lives within the urban cluster. The hinterland of a metropolitan area is defined as the worker catchment area of the urban labour market, outside the densely inhabited core. The size of the hinterland, relative to the size of the core, gives clear indications of the influence of cities over surrounding areas. Urban hinterlands are defined as all municipalities with at least $15 \%$ of their employed residents working in a certain urban core. Municipalities surrounded by a single functional urban area are included and noncontiguous municipalities are dropped.

The OECD definition is mainly based on economic characteristics and mobility related to the economic activities and is due to the nature of growth in the metropolitan areas. They are attractive because of their job provision and their higher level of productivity. They offer more job opportunities due to a wider and more flexible job market. They offer more possibilities for innovation because they are the main support of globalisation and the main beneficiary of this process.

With some cities having higher GDP than nation states, building a metropolitan governance is a very sensitive political process; London represents $50 \%$ of the United Kingdom's GDP, Paris 30\% of France's GDP. National governments are aware of this and limit or retain control of these areas, not only as they are a main engine 
for the economic growth of the country but also a source of legitimacy for politicians.

Some cities have large fragmentations of local administrations, as Paris metropolis with 1,276 municipalities, dozens of inter-municipalities, a 'Métropole du Grand Paris (Metropolis of Greater Paris)' that covers only $5 \%$ of the metropolitan area, eight departments and one region for 12 million inhabitants, making it difficult to create an efficient metropolitan governance. Others are more concentrated as Beijing with a single municipality for 22 million inhabitants. Building a process for establishing an efficient governance system can take decades, as experienced in Italy where 10 metropolises have been created after a long process. The support of a metropolitan planning agency is an essential tool to manage changing governance systems.

The enhancement of the communication infrastructures increases the influence of the urban core, redefining their hinterlands and becoming a potential asset for sustainable rural areas with their villages being integrated in the urbanisation process. The economic growth of rural areas at the peri-urban metropolis is higher than other rural areas. Development corridors between metropolitan areas providing economic opportunities along communication infrastructures. Cooperation between metropolitan areas and between local human settlements reduces costs for utilities and facilities, develops territorial solidarities and increases resilience facing economic and social crises.

Today 1,200 metropolises of over 500,000 inhabitants gathers more than $50 \%$ of the world urban population (United Nations 2018). The metropolis in different shapes and sizes is already the dominant pattern of human settlement. The megapolises, according to the UN definition with populations of over 10 million inhabitants, included only Tokyo and New York in 1950, while in 2018 there were 33 metropolises concentrating $12.5 \%$ of the world's urban population. Megalopolis or megaregions are gathering several metropolises within a single urban system. Leading these, are the Pearl River basin in Southern China, the Great Lakes and North-East coast in the USA, Tokyo-Osaka and the European Blue Banana each with more than 50 million inhabitants.

These metropolises and megaregions change the scale of human behaviour. Higher efficiency in mobility systems and larger concentration of population creates new conditions for human life with social melting pots generating new urban cultures. The identity of these large human settlements of limitless cities cannot be defined by administrative boundaries or a local power elected on the basis of territorial delineation. The question of a unique identity cannot compete with a so diverse social mix where multiple identities are emerging. Culture is the tool for the connexion between the identities and an essential element for building the society of large conurbations.

International networks of metropolises ${ }^{7}$ are very active in the global debate in promoting local development and the decentralisation processes of the urban-rural linkages. They exchange best practices for better management of their cities and lobby to catch more competencies and resources from the devolution processes of national governments.

The acceleration of new technologies, with some presented as disruptive innovation, offers opportunities to manage and develop large cities. E-governance makes easier the relationships at a large scale between citizens and decision makers. E-shopping changes the behaviour of the consumers, redefining the role of commercial malls and the urban logistic systems. Autonomous cars will have an impact on car usage and offer new opportunities to reshape public spaces. New technologies are mobilised to better manage large cities with smart grids increasing the efficiency of utilities and public services and reducing costs for operation and maintenance.

\section{Historic Urban Landscape and Territorial Planning}

UNESCO adopted in 2011 the Recommendations on the Historic Urban Landscape:

The historic urban landscape is the urban area understood as the result of a historic layering of cultural and natural values and attributes, extending beyond the notion of 'historic centre' or 'ensemble' to include the broader urban context and its geographical setting. This wider context includes notably the site's topography, geomorphology, hydrology and natural features, its built environment, both historic and contemporary, its infrastructures above and below ground, its open spaces and gardens, its land use patterns and spatial organisation, perceptions and visual relationships, as well as all other elements of the urban structure. It also includes social and cultural practices and values, economic processes and the intangible dimensions of heritage as related to diversity and identity. This definition provides the basis for a comprehensive and integrated approach for the identification, assessment, conservation and management of historic urban landscapes within an overall sustainable development framework (UNESCO 2011). 
This holistic approach is enlarging the historic centre in relation to its wider environment. It recognises that urbanisation is proceeding on an unprecedented scale confronting demographic shifts, global market liberalisation and decentralisation, mass tourism, market exploitation of heritage, and climate change. It focuses on extending the notion of the historic centre, making the link with local development processes and territorial planning in the application of a landscape approach.

However, HUL is not currently applied to a larger scale. It is currently targeting the necessity to take into consideration the larger environment to protect urban historic centres, but not to broaden the notion at the level of the metropolis.

\section{Landscape Approaches and Territorial Planning}

Territorial planning has existed for more than four millennia as it is evidenced in the archaeological surveys of Mesopotamia (Margueron 2013). With circle or grid shapes cities, the question of managing the physical development refers to the institutional capacities of societies to impose regulations and legal framework for organising the urban developments. Egyptians, Greeks, Romans, Persians, Hans, Mayas and Incas shaped their cities in well organised manners that are an integral part of their significant heritage, many times recognised through the World Heritage listing.

Contemporary territorial planning references new capacities, new concepts and new challenges. The industrial revolution transformed the communication systems, the production modes and the societal structures. Comprehensive planning was the industrial response applied to the physical organisation of cities where the Athens Charter and their followers developed the zoning of functions and the separation between pedestrian and motorised mobility. The functionalist approach was searching for economic efficiency and greater mobility. The result was an acceleration of the urban sprawl, social segregation, higher costs for infrastructures, greater pollution and traffic jams. Comprehensive planning viewed the urban development as an architectural project to be designed and then applied by phases. Society was analysed through models with planning applied in a topdown process, mainly by the national governments. This method in reality was inefficient, with plans partially implemented due to the lack of the capacities to impose their views on coalition of actors.

The liberalisation of the economies in the eighties required another approach, more dynamic, reducing the role of the national governments. Strategic planning was then focusing on large structures enhancing projects managed by a consortium of key players. Cities Alliance ${ }^{8}$, with the support of the World Bank and UN-Habitat developed the concept of city development strategies applied on dozens of cities in developing countries. Large urban projects, receiving most of the public and private investments, were encouraged under privatisation policies. Securing land ownership through land registration was a priority together with weak development control regulations to prevent discouraging investors. Less financial capacities were devoted to local governments with the resulting public debt being transferred to the private sector. The consequences were higher prices for users, higher benefits for private companies delivering public services, higher debts benefiting to the banking system, with low capacities of local governments for controlling the quality of delivered services.

With the increase of environmental concerns, landscaping methodology becomes more important in the planning processes as a holistic approach considering the landscape as a result of the different components of a territory. The economic forces, the mobility system, the demographic trends affecting housing requirements, the environmental constraints of flooding or landslides need to be articulated for a more harmonious implementation. The principle entails organising the territory from the non-built areas, shaping the areas by addressing water constraints, ecological corridors and visual or scenic concerns. Nature in the city should be a priority to better balance the built-up areas and pollutions with green solutions that mitigate the effects of the urbanisation and reduce risks.

But the approach needs to be more inclusive to tackle the sustainable development. Territorial planning is more adapted to the era of the metropolis where urban and rural areas are participating in the same development process. The economic functional approach is beyond the administrative limits. The territorial approach is both urban and rural. It provides the links between the functions, articulates territories together, coordinates the different vertical layers from national, regional and local administrations, and meshes the service sectors including health, education, water, mobility and energy.

\section{New Challenges for Territorial Planning}

There are new challenges on the eve of the $21^{\text {st }}$ century that will have a strong impact on planning and culture in the metropolitan areas. The present economy is dominated by financial assets where Wall Street values have doubled since the last 2008 financial crisis and will 
readjust in a rollercoaster pattern. The present economy is based on financial bubbles where an important part of the assets are invested in real estate and urban services engaging local savings and markets. Land and real estate prices increase without relation with the revenue of the inhabitants. Higher investments in city centres, business districts and new towns create conditions that exclude whole communities with inhabitants leaving well equipped city centres and jobs, to the suburbs without urban services and employment opportunities. This increases the need for public transportation and communication infrastructures resulting in a greater social and spatial segregation and where local and national governments struggle to provide social housing and finance public services. Private debt replaces public solidarity for the benefit of the private investors at the expense of the citizen. The effect of the disconnection between the needs for housing and jobs and these investments is seen in empty buildings and new towns, as the city centre of Beirut managed by a private company, dozens of empty new towns in Egypt, China, India, or many empty apartments in UAE or Saudi Arabia.

Moreover, climate change has become a major challenge of the $21^{\text {st }}$ century. Territorial planning is changing its priorities from higher car mobility to proximity, from urban expansion to urban renewal, from economic development to circular economy (UN-Habitat 2015). This transforms policies for territorial planning prioritising public transportation to reduce emissions, thereby reducing the number of cars in the city and adopting a compact city concept. It also highlights the need to address the vulnerabilities facing natural hazards by focusing on resilience, more control on prone areas and better governance during natural hazard crises.

The present changes in international relations foster economic and political confrontations with many conflicts in cities where most of the population are living. These conflicts may extend over decades as experienced in Lebanon, Afghanistan or Iraq. Urban management needs to take into account their duration and the potential for recovery and physical reconstruction related to reconciliation processes that are based on culture and the rebuilding of the social links.

Culture plays an important role in the recovery and reconstruction of cities after disasters, crisis and conflicts. In a joint Position paper published in 2018, UNESCO and the World Bank have identified several principles whereby culture should be recognised as the basis for building policies and strategies in the reconstruction process (UNESCO and World Bank 2018). In fact, cities being a cultural product with local assets are vital to support a reconciliation process after a conflict and build recovery after disasters thereby driving a new territorial planning approach.

\section{New Planning Approaches}

New planning approaches are developed due to these huge challenges. Conventional physical planning is more of a technical tool than a platform to support a dynamic process for managing urban and territorial developments. When citizen engagement becomes important, a technocratic top-down process is no longer relevant. The huge uncertainties of the future due to our economic paradigm based on financial bubbles and economic crisis, climate changes and new international relations make difficult to adopt any scenario for the future development of cities. Planning systems need to reinforce the capacity to understand behavioural change and be able to adapt its regulations to fast changing needs. Then, it is more important to set up territorial planning agencies to develop and share knowledge, support public debates and decision-making than to determine rigid master plans that linger for decades. Monitoring growth and change, based on goals and indicators with frequent revisions by feedback, strategies and policies is essential, engaging digital technologies for the analysis of behavioural and physical developments.

The metropolitan design process that apply the design thinking principles to the metropolitan planning, renew planning methodology with an iterative process between urban design and planning. It is a process of valorisation of the metropolitan scale through specific projects at the human scale.

The challenges of climate change are being addressed in the realms of urban heritage by UNESCO and ICOMOS (UNESCO 2008; UNESCO and UNEP 2016). ICOMOS $^{9}$ is currently preparing a paper outlining the interdependence of climate change and cultural heritage. It identifies various climate conditions as temperature changes, permafrost thaw, humidity change, wind, drought, higher precipitations, storms, sea level rise, ocean acidification, and their impacts on different categories of heritage as museums/collections, archaeological resources, building and structures, urban heritage and cultural landscapes, associated communities, and intangible cultural heritage. The objective is to define specific measures to protect the heritage facing the different effects of climate change and evaluate adaptive practices. Urban warming at the metropolitan scale needs new tools. 


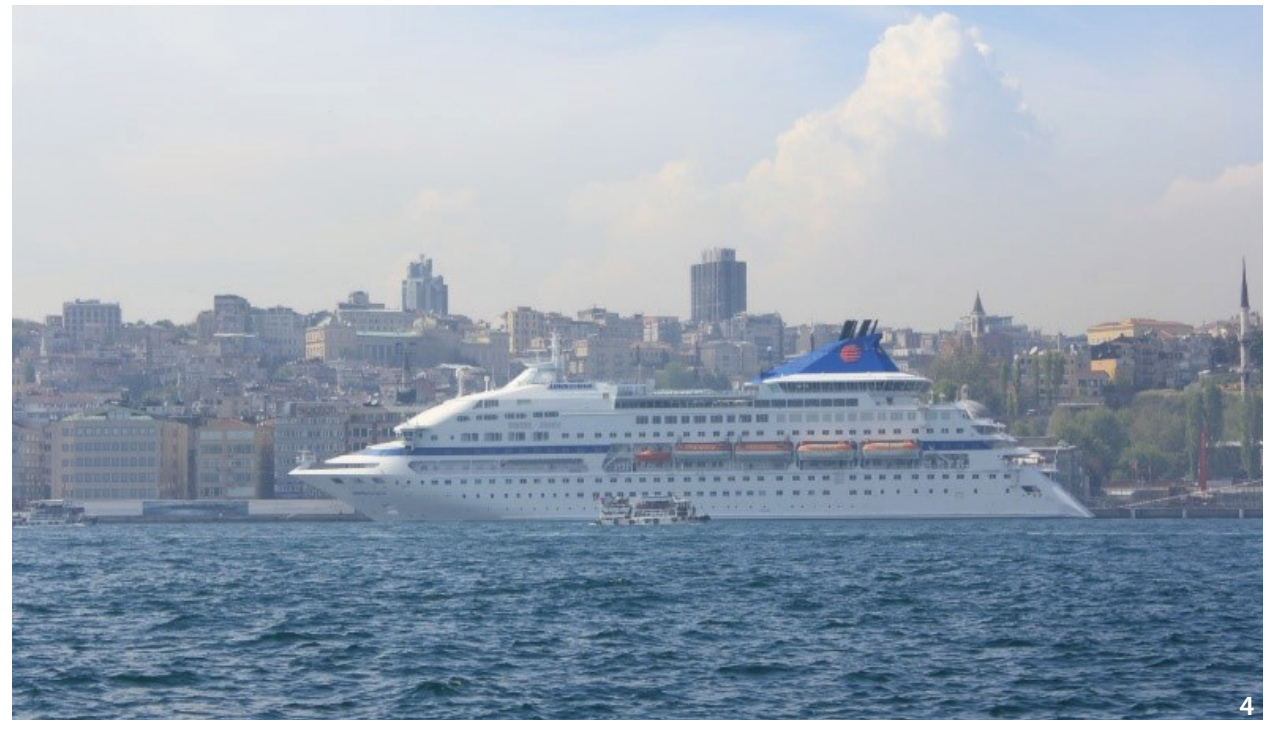

Figure 4 Culture policies: To reshape urban areas for positioning cities on the world map (Istanbul) (Source: the author).

\section{Culture Shaping the Metropolis}

The 2030 Agenda for Sustainable Development mentions clearly the natural and cultural heritage in the Target 11.4: 'strengthening efforts to protect and safeguard the world's cultural and natural heritages' (United Nations 2015). Culture is a fundamental asset to consolidate sectors and territories to make our cities safe, inclusive resilient and sustainable. Culture is the cartilage between identities, filling the gap between several polarities. It is the essence of a society, making possible the interrelationships between contradictory components.

Among others, there are three main drivers for cultural development of cities. Cultural policies and strategies of metropolitan areas are produced by local or national governments to promote their culture or to reshape the image of cities differentiating themselves from other cities. Large cities are developing public facilities as libraries (Seoul has 1,077), museums (Paris has 297) or art galleries (New York has 1,475). In principle, these cultural policies try to ease integration of marginalised groups and facilitate social inclusion, but sometimes have contradictory effects. They may also reshape the city through large urban renewal projects to refurbish decayed areas with a bottom-up process and evictions. Creative industries are a driver of change for producing urban projects within the city, by intensification of the urban areas, and then participating to the implementation of the compact city principle. In fact, large amount of money is spent on culture in Paris, Moscow and London, San Francisco, New York City and Shanghai by national and local governments and the private sector. Culture is also an economic driver creating jobs, with some $19 \%$ of the employment in London (WCCF 2018) (Figure 4).

\section{Identifying Metropolitan Heritage?}

Metropolitan heritage could become an extension of HUL given the importance of the metropolis that represents the main artefact of the human settlements of the $21^{\text {st }}$ century. So what could be a metropolitan heritage? There are several elements that characterise the metropolis that could become heritage values.

Some exceptional monuments are landmarks of the metropolis. For example, the Eiffel Tower in Paris, the Petronas Towers in Kuala Lumpur, the Forbidden City in Beijing, the Acropolis in Athens, the Statue of Liberty in New York, Corcovado in Rio de Janeiro, London Bridge or the Moscow Kremlin are iconic monuments used in the branding of these large cities. They represent their metropolis and should be considered as metropolitan components (Figure 5).

Historically, cities are located near water bodies-sea fronts, lakes and rivers. It is vital for providing fresh water and to facilitate communication. The relationships between these water bodies and the city are essential in considering their implication in the urban geo-morphology. Cities are transforming their interfaces with water bodies: the beaches of Rio de Janeiro, the waterfront of Barcelona, the canals of Amsterdam. Water bodies are an essential part of metropolitan features, revealing their human exchanges with the rest of the world as the river front of the Docklands in London.

Natural landscapes of the hinterland characterise the cities with the proximity of mountains or hill-ranges providing the image of the city as in Tokyo, Mexico, Montreal or Erevan. The National parks of Mumbai, Nairobi, Rio de Janeiro and Cape Town are all main assets for their cities. 

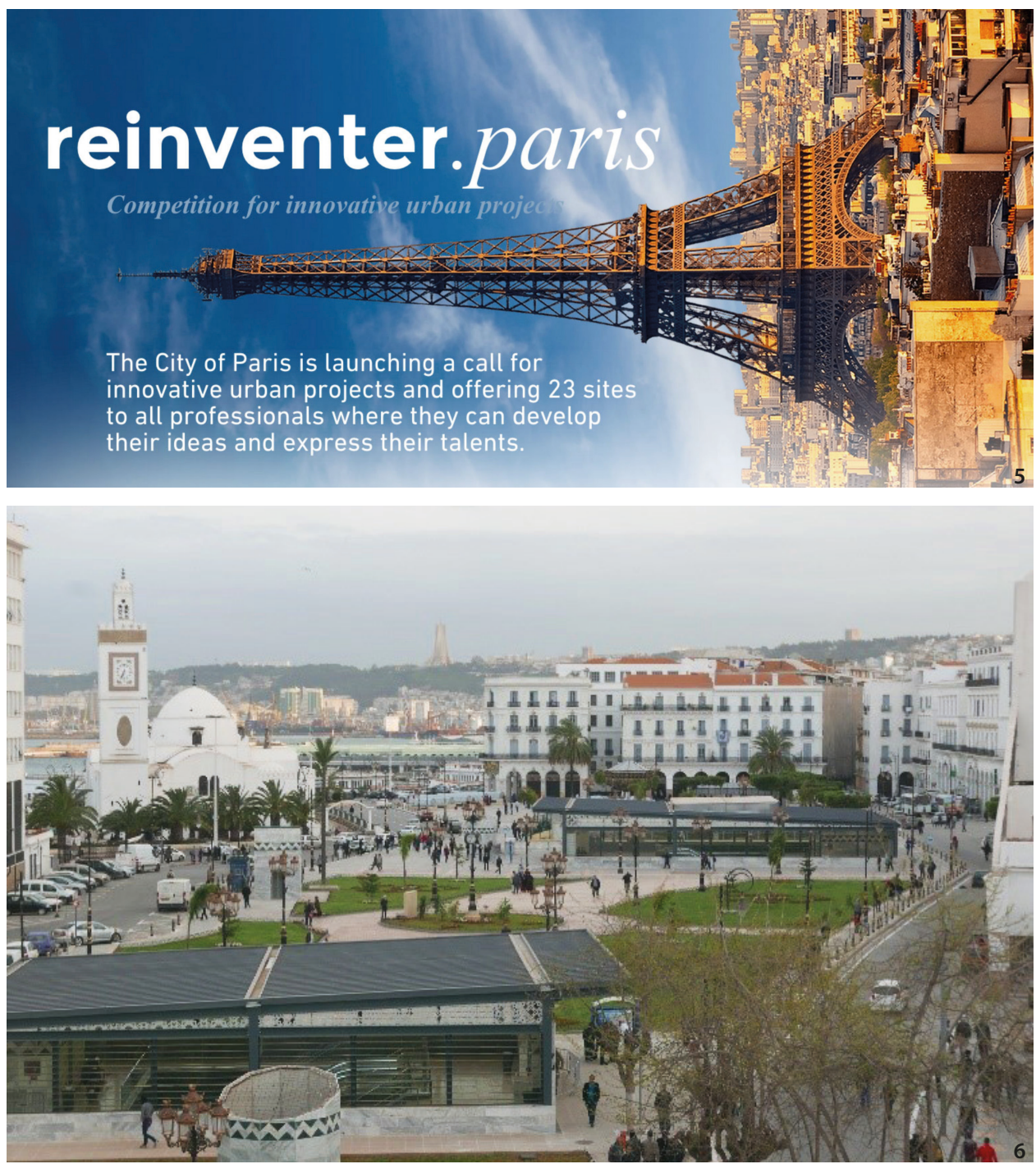

Figure 5 How metropolitan landmarks could reinvent cities (Source: Mairie de Paris). Figure 6 Historic urban centre to represent the metropolis, Algiers Martyrs Square (Source: Mairie de Paris).

Large green corridors that connect biodiversity between large forests or along the rivers structure the city also provide the mental map of the metropolis and its heritage.

Metropolitanisation is based on metropolitan artefacts as congress centres, central business districts, international airports, large ports, exhibition centres, large museums, opera houses, large commercial centres, university campuses, general hospitals. These artefacts are key components to support the dominance of the metropolis on its hinterland, compete with other large cities and provide for its identity and heritage.

Urban historic centres are sometimes a key asset for city branding and represent the metropolis as Venice historic city, the Kasbah of Algiers or the old town of Aleppo. This is not the case in all large cities where the historic urban centres are more limited and fragile, facing land and real estate speculation. Iconic public spaces as Times Square in New York, Tien'anmen Square in Beijing, Trafalgar Square in London, Luxembourg Park in Paris are used by most of the inhabitants and are the backbone of the metropolis.

Large infrastructures of public spaces provide the framework for the mobility of large cities. They are essential for city development and may be considered as the main characteristic of large cities. Motorways, rings and large radial highways, large boulevards and transportation infrastructure are also important and permanent features of large contemporary cities. Trains, metros and tramways are shaping cities with lines and stations. Around their stations large urban development projects occur benefiting from the high accessibility of these public investments. Some cities are implementing new metro lines that support strong urban renewal of their suburbs as in Paris and Moscow. The design of the transportation infrastructures and their integration in the urban context are key elements for the quality of life in the city and its future heritage (Figure 6). 
Landscape improvement, like the greening of large areas around the Istanbul historic peninsula along the Marmara Sea and the Golden Horn, or transforming motorways to pedestrian areas in city centres in Paris Seine riverbanks or Seoul city centre upgrades the city, increase its value and create new icons.

\section{Morphing the Metropolitan Components into Heritage}

The present paper outlines the importance of the metropolis in the contemporary context, as a key feature of the emerging human settlement being the new horizon of urbanisation. The recent approaches on territorial planning are in line with the present challenges regarding the importance of managing economic volatility, climate change and the transformations in international relations that are source of crisis, conflicts and disasters.

The Historic Urban Landscape provides a holistic approach regarding the urban historic centres being based on the landscaping approach that takes into consideration the environment, larger scales and the dynamic changes in the built heritage. It is in line with territorial planning as applied at the different scales and positions culture as a tool for inclusivity and sustainability.

This approach could be extended to the metropolitan scale. If heritage reflects the main features of humankind, the metropolis will be the dominant shape of built settlement with more than half of urban dwellers living in cities of more than 500,000 inhabitants. The identification of metropolitan characteristics could be the basis for preparing the recognition of its heritage, being the combined efforts of local and national government to enhance the quality of life and to give significance to their metropolis. It could also be a driver to foster new initiatives of local and national governments to develop their metropolises with more cultural values thereby transforming the metropolitan components into heritage and positioning culture as a driver of change for our cities.

\section{Notes}

1. For example, the Paris metropolis is equivalent to that of Saudi Arabia.

2. The effect of the financialisation of the economy, fuelled by stock exchange bubbles, is the over investments in real estates in large metropolises (London, Dubai, Phnom Penh, Beijing, Shanghai, Mumbai, Casablanca) without relating to the real needs for housing and jobs. This over speculation increases prices of land and real estate making large cities less affordable for the citizens and increasing duality inside cities. Some cities (Vancouver, Toronto) are introducing new taxes to reduce the impact of these investments.

3. For a good synthesis of the metropolitan issues, see: Co-creating the Urban Future: The Agenda of Metropolises Cities and Territories, UCLG, 2016, Barcelona.

4. For example, Paris Regional Planning Agency (www. iau-idf.fr), Seoul Institute, Regional Planning Association (New York), Emplasa (Sao Paolo).

5. More information see www.mtpa-network.org/

6. French Regional Natural Park corresponds to IUCN category V: Protected landscapes. See http://www. parcs-naturels-regionaux.fr

7. More information see www.metropolis.org

8. More information see www.citiesalliance.org

9. ICOMOS is preparing an 'Outline of Climate Change and Cultural Heritage' within a working group of 52 participants.

\section{References}

Charles-Edouard, Houillier-Guibert. 2012. "De la communication publique vers le marketing des territoires: approche microsociologique de la fabrication de l'image de marque." [From Public Communication to Territorial Marketing: A Micro-sociological Approach to Branding.] Gestion et management public 1 (2): 35-49.

Grange, Daniel J., and Poulot Dominique. 1997. Lesprit des lieux: le patrimoine et la cité [The Spirit of the Place: The Heritage and the City]. Fontaine: Presses universitaires de Grenoble.

Debarbieux, Bernard. 2012. Tourisme, imaginaires et identités : inverser le point de vue [Tourism, Imaginaries and Identities: Reversing the Point of View]. Geneva: Geneva University.

Margueron, Jean-Claude. 2013. Cités invisibles. La naissance de l'urbanisme au Proche-Orient ancien. Approche archéologique [Invisible Cities: The Birth of Urbanism in the Ancient Near East, Archaeological Approach]. Paris: Geuthner.

Lussault, Michel. 1992. "Tours: images de la ville et politique urbaine." [Tours: City Images and Urban Policy] Revue de géographie de Lyon 73: 373-385.

OECD (Organization for Economic Cooperation and Development). 2013. "Definition of Functional Urban Areas (FUA) for the OECD metropolitan database." Paris: Organization for Economic Cooperation and Development.

OECD (Organization for Economic Cooperation and 
Development). 2015. The Metropolitan Century Understanding Urbanisation and its Consequences. Paris: Organization for Economic Cooperation and Development.

UNESCO and UNEP. 2016. "World Heritage and Tourism in a Changing Climate." Paris: UNESCO and UNEP.

UNESCO and World Bank. 2018. "CURE: Culture in City Reconstruction and Recovery." Paris: UNESCO and World Bank.

UNESCO. 2008. Policy Document on the Impacts of Climate Change on World Heritage Properties. Paris: UNESCO.

UNESCO. 2011. "Recommendation on the Historic Urban Landscape." Accessed 24 December 2018. http://portal. unesco.org/en/ev.php-URL_ID $=48857 \% 26$ URL_ DO=DO_TOPIC\%26URL_SECTION=201.html

UN-HABITAT. 2015. International Guidelines on Urban and Territorial Planning. New York: UN-HABITAT.

United Cities and Local Governments. 2016. Co-creating the Urban Future: the Agenda of Metropolises, Cities and Territories. Barcelona: United Cities and Local Governments.

United Nations. 2015. "Transforming our World: The 2030 Agenda for Sustainable Development.” Accessed 24 December 2018. https://sustainabledevelopment. un.org/post2015/transformingourworld

United Nations. 2018. "World Urbanization Prospects: The 2018 Revision."

WCCF (World Cities Culture Forum). 2018. World Cities Culture Report 2018. London: BOP Consulting. 